\title{
Analysis on Efficiency Evaluation of Regional Energy-saving and Emission-reduction Based on DEA Model
}

\author{
Shuang Wang \\ Economics and Management College, Dalian University, Dalian, 116600, China \\ wshuang1021@sina.com
}

\begin{abstract}
Keywords: Energy-saving and emission-reduction; DEA; Evaluation index system
Abstract. Based on both at home and abroad energy sustainable development ,enterprise energy evaluation index system research and low carbon economic background, this thesis proposed the strategy thought of full process of energy-saving and emission-reduction, selected DEA evaluation method to achieve efficiency monitoring, followed the application steps of DEA evaluation method and built the evaluation index system for energy-saving and emission-reduction which contained inputs and outputs aspects of 8 items specific indicators. The thesis took Dalian as an example to discuss the running situation of energy-saving and emission-reduction strategy within each year and propose that only we strive to achieve industry upgrade in the future, develop circular economy and control the amount of energy input.
\end{abstract}

\section{Introduction}

The concept of "energy-saving and emission reduction" was first proposed in "Eleven-Five" program and made energy-saving and emission reduction work closely together. "Eleven-Five" program also proposed that "save resources should be as a basic state policy, developing circular economy, protecting the environment, and building a resource-saving and environment-friendly society and promoting harmony between economic development, population, resources and environment. " In 2007, NPC\&CPPCC focused on energy-saving and emission-reduction again, and claimed that energy-saving and emission-reduction was a main line through socio-economic development in our country. At this point, energy-saving and emission-reduction is a hot topic nowadays, is used to increase energy level and ensures energy security as well as the major problems in China's economic and social development.

\section{Literature Review}

There were a lot of researches on energy-saving and emission-reduction, energy efficiency, environmental auditing and low-carbon economy abroad and have achieved fruitful results. Thomson (1994) considered that environmental audit can assess the resource consumption and environmental impact and inspect the management system of enterprise periodically as well as adjust follow-up activities and so on. Flemish Government (2004) considered that environmental audit was a systematically and objectively assessment to management associated with environmental protection and organization of activities. World States and international related organization has proposed some guidance which related to energy-saving and emission-reduction and environment audit. CICA in Canada has listed energy-saving and emission-reduction and audit evaluation in different industry, in which multiple aspects of energy-saving and emission-reduction and audit evaluation indicators was included in utilities, manufacturing, and traffic industry etc. These indicators could become reference indicators for Enterprise to evaluate energy-saving and emission-reduction and audit evaluation.

There were some domestic scholars engaged in research on energy-saving and emission-reduction, in which explode with excellent results. There are some respective figures: Wang $\mathrm{Li}$ (2013) described the current China's SMES current situation of energy-saving and emission-reduction from advancing the importance of energy saving, and concluded that energy conservation and emissions reduction is the needs of enterprise development. Compared with 
promoting the fiscal and tax policies to energy-saving and emission-reduction in major countries, Song Xiaojing (2012) proposed that more comprehensive market system can make fiscal policy to play a role better and carried out both positive incentives and adverse constraints in fiscal and tax policies.

Fan Xinxing (2013) set up two sets of evaluation index system of quantitative and qualitative and provided fuzzy mathematical thought that attempts to implement energy saving environmental audit supervision in China from the energy-saving and emission-reduction and environmental audit perspective. Based on energy-saving and emission-reduction and dynamic evolution model, Tian Lixin combined with scenario analysis to predict economic output, energy consumption and pollution emissions for Yangtze River Delta area in 2015, and analyzed economic output, energy consumption and pollution emissions evolution in 2009-2015. Liu Yuanming and his colleagues built fuzzy evaluation model for energy-saving and emission-reduction in coal enterprise using analytic hierarchy process and fuzzy comprehensive evaluation method.

\section{The Brief Review of Evaluation Method}

Data envelopment analysis, DEA has developed into a kind of non-parametric frontier efficiency analysis method on the basis of the relative efficiency evaluation by A.Charnes and W.W.Copper scholars etc. this method is often used in input and output system of the production and living for management, decision-making and efficiency and benefit evaluation, etc, at present which has become a widely used and effective analysis tool in the field of management science and system engineering. It mainly uses the linear programming method, on the basis on the original sample data are divided into input index and output index, gets to evaluate effectively to decision making units(DMU), for the purpose is to reflect whether the DMU can achieve the decision-making results of "spending as little as possible, to get maximum benefit".

CCR model is the basic model of DEA, and BBC model could improve and optimize of the CCR model, which improves more than CCR in all aspects. Mainly, the CCR model assumes constant returns to scale, but in practice because of some external conditions, such as the limitation of the legal regulation and imperfect competition, etc, output units are unable to achieve the efficiency of the constant returns to scale. So, the study chooses the BBC model based on input as analysis model.

\section{Construction Evaluation Index System and Application Steps of DEA}

\section{Establishment of Index System on Input-output}

The evaluation index system is an information system since it reflects specific evaluation volume levels and the size of the object multiple perspectives and hierarchy. The first step of construction on the system is that applied system structure and then configured subsystem elements, namely, the identification of a single indicator, in order to make the whole system become an interconnected and integrated system. According DEA model requirements, we need to set both input and output targets, and then think of the connotation of energy-saving and emission-reduction requirements, and define 8 specific indicators totally, as shown in table 1. 
Table 1 The Evaluation Index System of Energy-saving and Emission-reduction

\begin{tabular}{|c|c|c|c|}
\hline General target & $\begin{array}{l}\text { First grade } \\
\text { indicators }\end{array}$ & Second grade indicators & $\begin{array}{l}\text { Index } \\
\text { coding }\end{array}$ \\
\hline \multirow{8}{*}{$\begin{array}{l}\text { Evaluation } \\
\text { index system } \\
\text { for } \\
\text { energy-saving } \\
\text { and emission } \\
\text {-reduction }\end{array}$} & \multirow{7}{*}{ Input index } & Raw coal consumption(10000ton) & A1 \\
\hline & & Crude oil consumption (10000ton) & A2 \\
\hline & & Heat consumption(ten billion $\mathrm{KJ}$ ) & A3 \\
\hline & & Electricity consumption(100million KWh) & A4 \\
\hline & & Wastewater emission(10000ton) & A5 \\
\hline & & Waste gas emission $\left(100\right.$ million $\left.\mathrm{m}^{3}\right)$ & A6 \\
\hline & & Solid waste production(10000ton) & A7 \\
\hline & Output index & Total industrial output value(100million yuan) & B1 \\
\hline
\end{tabular}

This system follows the principles of construction index system, which contains inputs and outputs. And it also has some research value in which the structure is simple and practical as well as could evaluate the efficiency of energy-saving and emission-reduction by using DEA model.

\section{Application Steps of DEA Model}

Application steps of DEA evaluation method are shown in Fig.1:

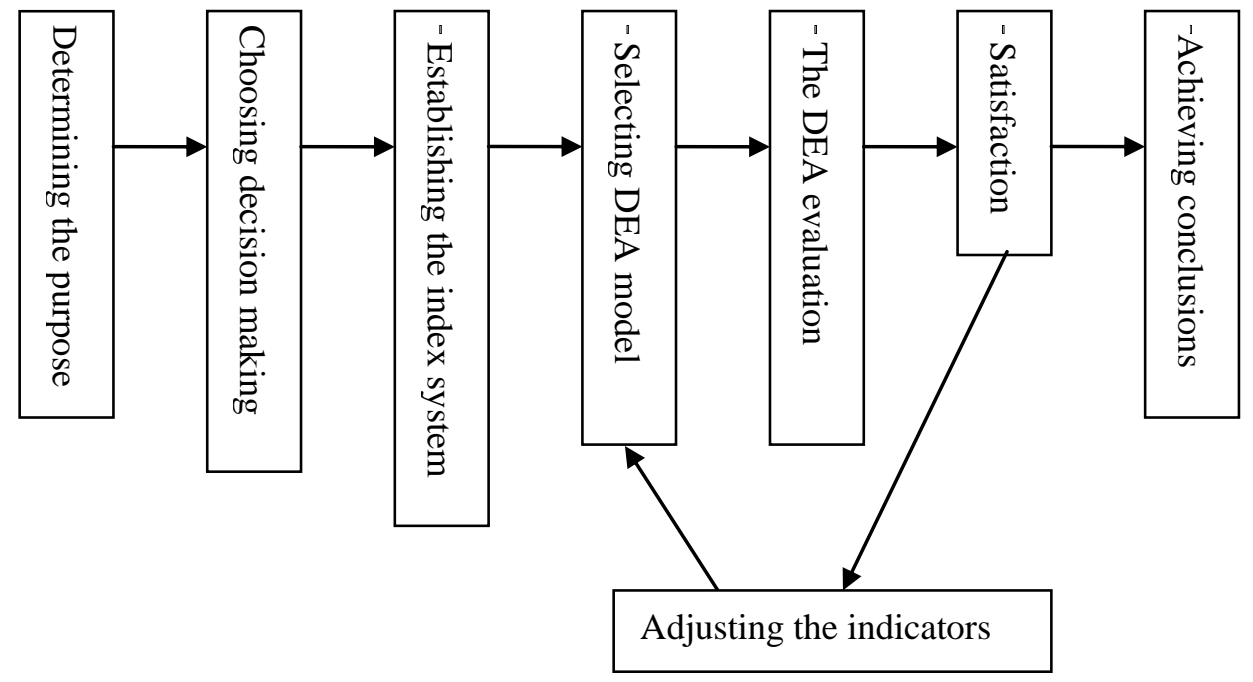

Fig.1 Application Steps of DEA Method

First is to determine the purpose; the purpose of this paper is to take Dalian as an example to realize analysis effectiveness of regional energy conservation; Second is to choose DMU, the target is to evaluate the efficiency of energy-saving and emission-reduction in Dalian City between 2005-2012, and then the DMU is for specific years; Third is to establish the system of input and output which are shown as in the figure; The fourth step is to select the BBC model of DEA after the above research thesis; Next is to carry out the DEA evaluation analysis and to distinguish the feasibility of evaluation; The last step is to achieve conclusions of the comprehensive evaluation analysis. 


\section{Analysis of Model Results}

The thesis evaluated the overall efficiency of energy-saving and emission -reduction by using BBC model in which pollutants as inputs for nearly 8 years in Dalian City and by using DEA software deap2.1 to run the results shown in table 2.

Table 2 The Results of the Annual Evaluation of the Energy-saving and Emission-reduction

\begin{tabular}{|l|l|l|l|l|}
\hline Year & Crste & Vrste & Scale & Returns to scale \\
\hline 2005 & 0.702 & 1.000 & 0.702 & irs \\
\hline 2006 & 0.790 & 1.000 & 0.790 & irs \\
\hline 2007 & 0.991 & 1.000 & 0.991 & irs \\
\hline 2008 & 1.000 & 1.000 & 1.000 & - \\
\hline 2009 & 0.958 & 0.989 & 0.968 & irs \\
\hline 2010 & 1.000 & 1.000 & 1.000 & - \\
\hline 2011 & 1.000 & 1.000 & 1.000 & - \\
\hline 2012 & 1.000 & 1.000 & 1.000 & - \\
\hline
\end{tabular}

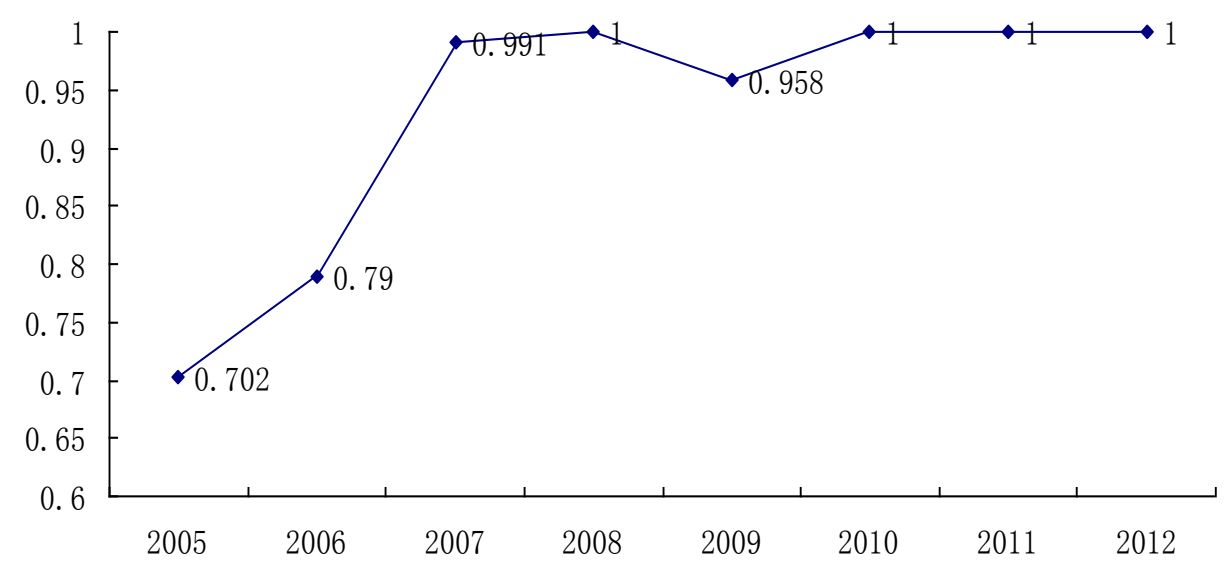

Fig.2 The Input-output Efficiency Value of Energy-saving and Emission-reduction in Dalian

Comprehensive technical efficiency values increased in 2005 to 2008, but decreased slightly in 2009 , this change was mainly influenced by the effects of the financial crisis of 2008. Global financial crisis first hit manufacturing industry in Dalian 2008.

Middle and lower reaches of industries was worst affected by it, such as textiles, metallurgy, paper making, building materials, machinery and electronics, chemicals and other industries, and then spread to energy and raw materials consisting mainly of upstream industries, such as coal, crude oil, iron ore, etc.. Energy and economic efficiency index were important factors to measure energy efficiency, therefore, the comprehensive efficiency of energy-saving and emission-reduction decreased in Dalian 2009.

From the results of table 2, most of the industrial energy-saving and emission-reduction was in order of decreasing returns to scale, namely, adding more inputs only could decrease outputs. From an economic point of view, decreasing returns to scale phase is the best level in the development of economic system, which claims that industry within energy and pollutants has already reached maximum in Dalian and thus cannot add to any more. Increasing in energy input would inevitably bring about contaminants; therefore, industrial energy-saving and emission-reduction in Dalian should be focused on how to reduce energy inputs to develop a circular economy. 


\section{Acknowledgement}

This research was supported by Social Science Foundation of Liaoning Province (L13DTJ005).

\section{References:}

[1]Qian Heping, Analysis and Evaluation Index System of Regional Energy-saving and Emission-reduction Based on DEA Model [J]. Science \&Technology Vision, 2013(9)

[2]Lu Yubo, Guo Bin, Evaluation on Efficiency of Energy-saving and Emission-reduction Based on DRF \& SE-DEA Model [J].Communication of Finance and Accounting,2013(9)

[3]Zeng Lin,Zhang Tianzhu, Research on Effect of Circular Economy and Energy-saving \&Emission- reduction Policy to Environmental Pressure in China [J]. Journal of Tsinghua University,2012,52(4)

[4]Zhang Dan,ect. Comparative Research on Regional Performance and effect of Energy-saving \&Emission- reduction in Chiba [J]. China Population Resources and Environment,2012,22(11) 